\title{
Congenital block vertebrae (C2 \& C3) and its clinical significance-A case report
}

\author{
Ramasamy Subbulakshmi, Sathiya Narayana Murthy
}

Subbulakshmi R, Murthy SN. Congenital block vertebrae (C2 \& C3) and its clinical significance-A case report. Int J Anat Var. 2019;12(4): 60-62.

The skeletal anomalies of cervical region are of interest to the anatomists, orthopedicians, neurologists, neurosurgeons, physiotherapists, and even orthodontists. These abnormalities cause severe neck pain decreased neck range of motion, muscle weakness and sensory defects over the upper extremities. The present study is to analyse the fused axis (C2) and third cervical (C3) block vertebrae and its clinical importance. During our routine osteology demonstration in the Department of Anatomy at Vivekanandha Dental College for Women, it was observed that the complete fusion of body, pedicles, laminaes of axis vertebrae with the third vertebrae on both anterior and posterior aspects. We analysed the features of block cervical vertebrae and the specimen was photographed in different views. This block vertebrae has its embryological and clinical implications.

Key Words: Block vertebrae; Cervical vertebrae; Foramen transversarium; Pedicle; Laminae; Axis

\section{INTRODUCTION}

Cervical vertebrae are seven in number. $\mathrm{C} 1, \mathrm{C} 2$ and $\mathrm{C} 7$ are atypical whereas C3-C6 are typical vertebrae. C2 vertebrae is different from the others with the presence of dens or odontoid process from the superior surface of body. Dens act as a pivot which allows the head and atlas to rotate around it [1]. The third cervical vertebrae (C3) is a typical with similar features of other cervical vertebrae. Congential anomalies are common in the vertebral column [2]. Two adjacent vertebrae are osseously fused from birth called congential block vertebrae. The most common fusion is between second and third cervical vertebrae. The congenital block vertebrae (C2 \& C3) limits the movement between these bones and because of this, the third vertebrae is called as "vertebrae critica" by Cave [3]. Embryologically, this is the result of failure of the normal segmentation process of the somites during the period of differentiation at 3 to 8 weeks. The presence of block vertebrae is not necessarily accompanied by clinical symptoms but may also appear with manifestations of serious clinical features such as myelopathy or may be associated with syndromes such as klippel-feil [4-6], crouzon's syndrome [7], limitation of neck movement [8], or the muscular weakness, atrophy and neurological sensory loss [9]. This anomaly is of clinical importance, thorough evaluation must be done by X-ray or Magnetic Resonance Imaging (MRI) for preventing any serious damage such as osteoarthritis by early diagnosis and treatment. The present study is aimed to study the congenital block (C2 and C3) vertebrae and its clinical importance.

\section{CASE REPORT}

During the routine osteology demonstration of cervical vertebrae for the first year BDS students in the Department of Anatomy at Vivekanandha Dental College for Women, it was observed that there was a complete fusion of vertebrae arches of both sides along with fused inferior articular facet of $\mathrm{C} 2$ and superior articular facet of $\mathrm{C} 3$. The features of this congenital block vertebrae was analysed and the specimen was photographed in different views (Figure 1).

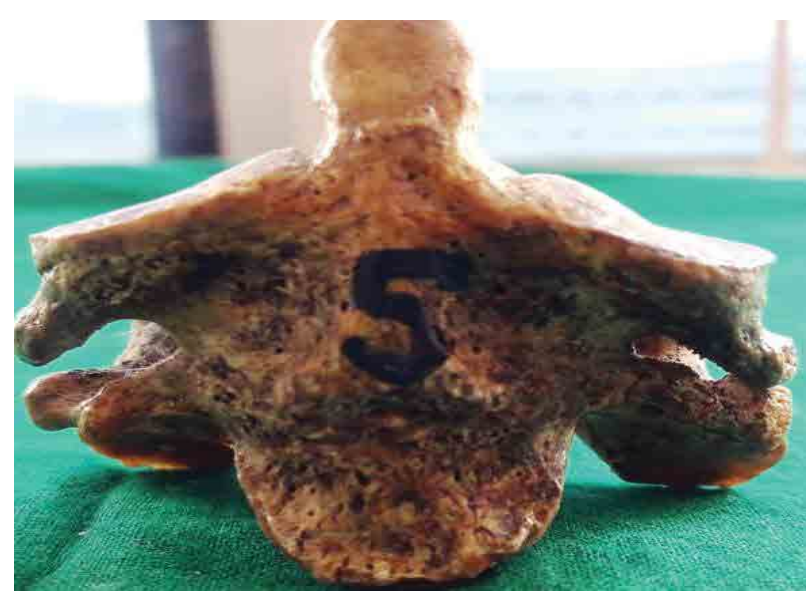

Figure 1) Shows fused bodies of $\mathrm{C} 2 \mathcal{E} \mathrm{C} 3$ vertebrae from anterior aspects.

\section{Observations}

Body, laminae and spines of $\mathrm{C} 2$ and $\mathrm{C} 3$ were completely fused on both anterior and posterior aspects (Figure 2). Pedicles were not fused. Transverse process is fused on right side and it is not fused on left side.

Foramen transversarium were present, and the diameter in $\mathrm{C} 2$ on the left side measured $7 \mathrm{~mm}$ and on right side $6 \mathrm{~mm}$. Foramen transversarium in C3 on the left side measured $9 \mathrm{~mm}$ and on the right side it was $7 \mathrm{~mm}$. The diameters were measured from inferior aspect in $\mathrm{C} 3$ and from the superior aspect in $\mathrm{C} 2$.

\section{EMBRYOLOGICAL SIGNIFICANCE}

Normal segmentation of the sclerotomes is important for the development of a normal vertebral column. Second cervical sclerotome give rise to

Department of Anatomy, Vivekanandha Dental College for Women, Tiruchengode, Namakkal (dt), Tamil Nadu, India

Correspondence: Dr. Ramasamy Subbulakshmi, Department of Anatomy, Vivekanandha Dental College for Women, Tiruchengode, Namakkal (dt), Tamil Nadu, India, Telephone+09943688250; E-mail: ursubbulakshmi@rediffmail.com Received: Jul 29, 2019, Accepted: Nov 22, 2019, Published: Nov 29, 2019 org/licenses/by-nc/4.0/), which permits reuse, distribution and reproduction of the article, provided that the original work is properly cited and the reuse is restricted to noncommercial purposes. For commercial reuse, contact reprints@pulsus.com 


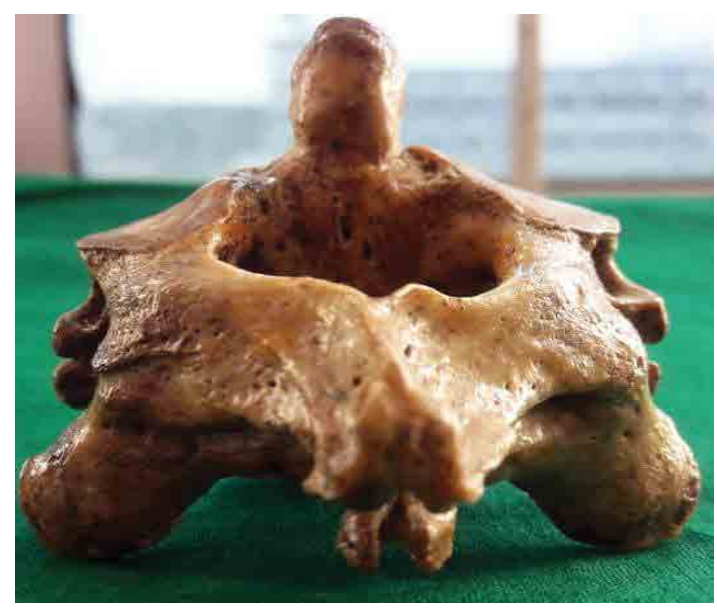

Figure 2) Shows fused spines of $\mathrm{C} 2 \mathbb{E} \mathrm{C} 3$ vertebrae from posterior aspects

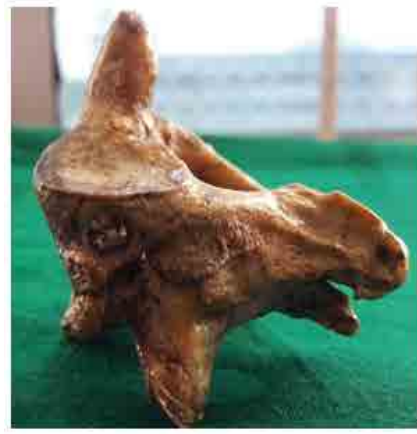

RIGHT LATERAL VIEW

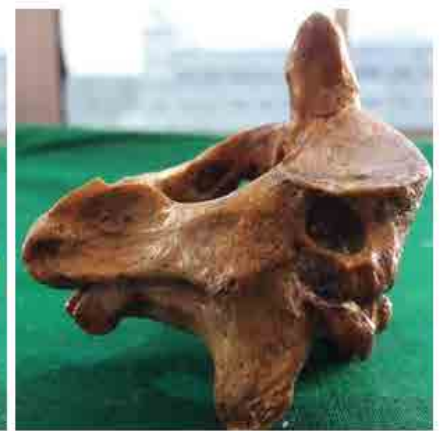

LEFT LATERAL VIEW
Figure 3) Shows fused right side transwerse process $\mathcal{E}$ failure fusion on left side transverse process of $\mathrm{C} 2 \mathbb{E} \mathrm{C} 3$ vertebrae from lateral aspects

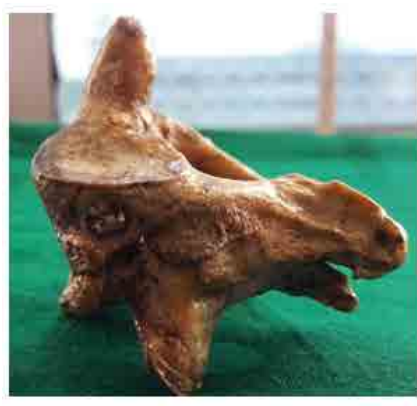

RIGHT LATERAL VIEW

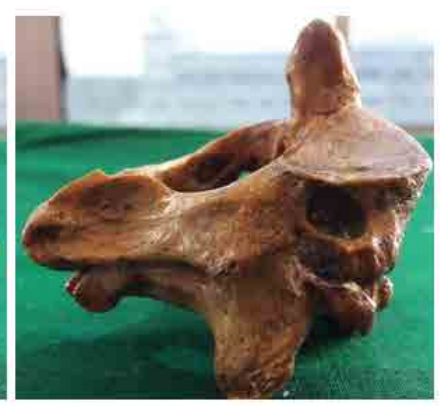

LEFT LATERAL VIEW
Figure 4) Shows vertebral canal and foramen transversarium of fused C2 $\mathfrak{E}$ C3 vertebrae from superior and inferior aspects.

the development of body, transverse process, and posterior arch of $\mathrm{C} 2$ vertebrae, tip of dens derived from cranial half of first cervical sclerotome [10]. Embryological failure of normal spinal segmentation due to decreased local blood supply during the third to eight week of fetal development results the block cervical vertebrae. Vertebral fusion anomalies are likely to be associated with disturbance of pax-1 gene expression in the developing vertebral column [11]. The common site of block vertebrae is between C2 \& C3 with the incidence of $0.4 \%$ to $0.7 \%$ of both sexes [12].

\section{CLINICAL SIGNIFICANCE}

While doing endotracheal intubation, extension of the neck is done. So persons with block vertebrae in cervical region have to take care to prevent hyperextension as it can precipitate disc prolapsed. If cisternal puncture is to be done, we should look for possibility of block vertebrae in cervical regions.

\section{DISCUSSION}

Block cervical vertebrae or fused cervical vertebrae have clinical and embryological importance. These block vertebrae appear both structurally and functional as one. This fusion may be congenital or acquired (Figure 3) [13]. Acquired block vertebrae may be due to diseases like tuberculosis, infections, juvenile rheumatoid arthritis and trauma. The presence of block vertebrae is not necessarily accompanied by clinical symptoms but may also cause neurological disturbances or may reinforce the effect of trauma. They also predispose to early spondylosis [14]. The anomalies of the cervical region are of interest to anatomists, orthopedists, neurologists, neurosurgeons, and even orthodontists. Nayak, had been reported the bilateral absence of foramen transversarium in atlas and explained the knowledge of this variations may be of importance during interventions in various disciplines like orthopedic surgery, neurosurgery, radiology and anthropology [15].

The early diagnosis is on incidental radiological findings. According to Farmen and Escobar, the radiographic appearance of congenital anomalies of vertebral bodies may be due to defects in fusion or normal segmentation, occipitalization of the atlas, odontoid process and atlas malformations, spina bifida and abnormal ossifications. There is increased osteophyte formation in the adjacent levels in cervical fusion. Upto $70 \%$ of occipitalization have an accompanying C2-C3 fusion with instability at the C1-C2 articulation (Figure 4) [12]. The motions of the neck and head like flexion, extension and lateral rotation of neck were decreased. A recent report suggests that long standing congenital or acquired fusion of upper cervical vertebrae may lead to stretching and laxity of ligaments between the occiput and atlas, resulting in excessive motion and brainstem or cord compression [16]. The presence of block vertebrae results in a greater biomechanical stress in the adjoining segment leading to the complications like disc tear, rupture of the transverse ligament, fracture of odontoid process and spondylosis $[12,17]$.

\section{CONCLUSION}

In our study, the right side transverse process fusion may leads to neurological complications like sensory defects and pain in head, neck, shoulders and both upper limbs with muscle weakness. Other features such as shortening of spine, prominent trapezius muscles, osseous malformations such as scoliosis and kyphosis. Management includes lifestyle changes to prevent and delay aggravation or the use of non-operative measures such as cervical collars or traction. Surgical intervention has a high risk of morbidity and mortality. Early diagnosis of these anomalies will be helpful in motivating the patients to change their lifestyle to normal life and to prevent the progression of degenerative process.

\section{REFERENCES}

1. Standring S. Gray's Anatomy, $39^{\text {th }}$ Ed, Eleviser Churchill Livingstone. 2005;742-744.

2. Romanes GJ. Cunnigham's Text book of Anatomy. 12 ${ }^{\text {th }}$ Ed. Oxford University press (Oxford): 1981;90-8.

3. Yadav Y, Goswami P, Bharihoke V. Cervical Vertebra Synostosis (C2C3)-A Case Report. J Anat Society London. 1937;72:319.

4. R Graaff. Congenital block vertebrae $\mathrm{C} 2-3$ in patients with cervical myelopathy. Acta Neuro chirulogy. 1982;61:111-26

5. Schlitt M, Dempsey PJ, Robinson RK. Cervical Buttefly Block Vertebrae: a case report. Clin Imaging. 1989;13:167-170.

6. Nagashima H, Morio Y, Teshima R. No neurological involvement for more than 40 years in Klippel-Feil syndrome with severe hyper mobility of the upper cervical spine. Arch Orthop Trauma Surg. 2001;121:99-101.

7. Kreiborg S. Crouzon syndrome. A clinical and roentgen cephalometgric study. Scand J Plast Reconstr Surg Supp. 1981;18:38.

8. Bharucha EP, Dastur HM. Craniovertebral Anomalies: a report on 40 cases. Brain. 1964;87:469-80.

9. Kameyama T, Ando T, Fukatsu H, et al. Syringomyelic syndrome secondary to cervical canal stenosis and cervical, spondylosis. Rinsho Shinkeigaku. 1993;33:1179-83.

10. Jayanthi V, Kulkarni R, Kulkarni RN. Atlanto occipital fusion-report of two cases. J Anat Soc India. 2003;52;71-3.

11. David KM, Coop AJ, Stevens JM, et al. Split cervical spinal cord with Klippel-Feil syndrome: seven cases. J Neurol. 1996;119:1859-72.

Int J Anat Var Vol 12 No 4 Dec 2019 
12. Soni P, Sharma V, Sengupta J. Cervical vertebrae anomalies-incidental findings on lateral cephalograms. Angle Orthod. 2008;78:176-180.

13. Erdil H, Yildil N, Cimen M. Congenital fusion of cervical vertebrae and its clinical significance. J Anat Soc India. 2003;52:125-7.

14. Young AC. Radiology of the cervical spine. In: Cervical spondylosis, $2^{\text {nd }}$ ed. (Wilkinson M. ed.). London; William Heinemann. 1970;106-112.
15. Nayak S. Bilateral absence of foramen transversarium in atlas vertebra: a case report. Neuroanatomy. 2007;6:28-9.

16. Yochum T, Chad M. C2 to C3 Congenital Block Vertebra. Am J Med Case Rep. 2010.

17. Tiwari A, Chandra N, Naresh M, et al. Congenital abnormal cervical vertebrae- a case report. J Anat Soc India. 2002;51:68-9. 